\title{
Research on Human Resource Matching Problems in Mergers and Acquisitions
}

\author{
Meng Zhail, a , Yong Qi ${ }^{2}$ \\ ${ }^{1}$ School of Management Science and Engineering, Shandong Normal University, Ji'nan 250014, \\ China \\ ${ }^{2}$ School of Public Administration, Shandong Normal University, Ji'nan 250014, China \\ aTaku751029@Hotmail.com
}

\begin{abstract}
Keywords: M\&A, Human resources matching, Lenovo, Risk.
Abstract. M\&A activities of Chinese enterprises have been increasingly frequent in recent years, and China is becoming an active country of M\&A in the Asia-Pacific region. China's accession to WTO has significantly sped up the process of integration into the world economy. Foreign M\&A has become a new way to China to attract foreign investment Nevertheless, Mergers and acquisitions also bring some problems, such as human resource risks that exist on corporate mergers and acquisitions which we need to study strategic approach to address the problems in order to promote the healthy development of the enterprise after the merger, which is of great significance to both enterprises and country.
\end{abstract}

\section{Introduction}

M\&A (Mergers and Acquisitions) activity has a long history but a late start in China, but its growth rate is faster than that of Western developed countries. Since the first occurrence of M\&A in 1984, M\&A between enterprises has become increasingly diversified which has been rapidly developing in general? At the same time, a variety of problems of M\&A between enterprises also appeared and the study of problems of benefits proper understanding of our business and M\&A activities.

M\&A includes two meanings: mergers and acquisitions. According to international practice, mergers and acquisitions are used in combination, collectively referred to as M\&A. According to the authoritative "Encyclopedia Britannica", the interpretation of the word "merger" is: "Two or more independent enterprises merged to form one company, usually consists of a dominant company to absorb one or more. The approaches are: (1) purchase with securities, cash or other assets of the company; (2) purchase shares or stocks in other companies; (3) issue new shares to other shareholders of the company to in exchange for their equity holdings, thus obtain additional company's assets and liabilities.”

In the M\&A process in large multinational corporations, human resource factors tend to become one of the most crucial factor in the success of mergers and acquisitions. This is because only full attention is given to the status of human resources of enterprises to be merged can key issues be found, thus avoiding mergers and acquisitions fail. Joseph carat Ringer's studies who is an U.S. merger specialist show that, based on post-mortem analysis, only about 35\% of mergers and acquisitions can achieve the intended target while most have failed to achieve the target acquisition due to human resource factors, so the ability to deal with matching problems of M\&A and human resource is directly related to the development of enterprises.

\section{Analysis of M\&A}

China has integrated into the world market step by step, and the phenomenon of domestic and international mergers and acquisitions has been enhanced. On the one hand, foreign enterprises enter China through mergers. On the other hand, Chinese companies have begun to go abroad to conduct overseas mergers and acquisitions: Lenovo took over IBM's personal computer (PC) arm, TCL acquired Germany Schneider and the TV operation of France's Thomson and CNOOC is on its way. Mergers and acquisitions are constantly carried out, and really start to show new features. 
M\&A has swept across the world and become an important pattern of global investment. The boom of foreign mergers and acquisitions reflects additional requirements on the allocation of resources for regional development and integration of the world economy. The current mergers and acquisitions abroad tend to be powerful and horizontal combinations. In the development process of M\&A, there had been horizontal mergers, vertical mergers and mixed, etc. In the 1980s, foreign business came into their fourth tide of mergers and acquisitions of the development process and their business strategy shift from specialized operation to strategies of diversification. In this way, mergers and acquisitions in this period are largely cross-industry and vertical. In the mid-nineties, with the advent of the fifth wave of mergers and acquisitions, foreign business shift from strategies of diversification to specialize operation. Accordingly, mergers and acquisitions were mainly concentrated on the uniform industry. Meanwhile, in the fifth wave of mergers and acquisitions, mostly objects were competitive enterprises and many enterprises treated their biggest competitors in the industry as a merger target, and these companies are also willing to serve as merged.

In the next few years, an inter-including overseas mergers and acquisitions climax are planned for China. Overseas investment and merger regulations will solve various problems which domestic enterprises have encountered in China and foreign acquisitions. What's more, foreign-funded enterprises in China should be built into the acquisition of state-owned enterprises and private enterprises. Asset assessment methods should be scientific and reasonable on overseas mergers and acquisitions. Mergers and acquisitions will be closely associated with the adjustment of industrial structure: industry mergers and acquisitions ratio will drop, and the proportion of tertiary industry and high technology will continue to increase. There will be the rapid expansion of the scale mergers and acquisitions, not only involving the rising amount, but also upgrading from horizontal to vertical and then mixed. Merger-related legislative environment will be continually improved and showed even more relaxed posture.

Pace of mergers and acquisitions in the 21st century will increasingly grow fast, and so do the transaction amount. Mergers and acquisitions are not limited to domestic enterprises, multinational mergers and acquisitions in the 21st century are extremely active. The speeding up of the globalization and the elimination of barriers to trade and investment, mergers and acquisitions has become an international behavior. It is not just an essential way for enterprises to achieve rapid expansion of low-cost, but also another driving force of economic growth.

For Lenovo, the domestic market did not have enough space for progress. It is important to move towards the world. The acquisition of IBM's machines cannot only contribute to improving the international status of IBM's brand and image, acquire IBM's R\&D, technology, and new channels and sales system will also pave the road at the pace of internationalization to some extent.

From Lenovo's perspective, despite IBM's PC business is declined, it is still of great value for the association. First, there are expanding production capacity, increasing market share, and improving product quality. Second, it is achieving operations' globalization. Finally, but not least, it is enhancing the management level and technical strength of the association and promoting global management talent.

\section{Human Resources Matching Problems of Lenovo Acquisition and Solutions}

Studies show that 58\% of the acquired company's management left the company in five years, while another $47 \%$ and $75 \%$ of senior managers were leaving in one year to three years. What's more, usually the senior management and the company's best talent will be the first to try to find a way out, resulting in the occurrence of "bad money drives out good money" phenomenon.

In fact, one of the core elements of Lenovo's acquisition of IBM PC is to buy excellent human resources. Management guru, Peter Drucker, has long warned that executives is the boss in the past and they do not want to become a business manager, so the thought that you can "buy" the management is impractical, and the buyer must prepare the loss of senior management teams .

According to reports, around the inside of IBM PC division, a lot of employees also have the idea of leaving. Many people's idea is that instead of waiting for Lenovo to lie off, and it is better to seek a 
new job by them. Some employees even have eaten disband dinner after hearing the merger news. Identifying and retaining key talent and core executives will be the main challenge facing the new Lenovo.

As a form of corporate change, Mergers and acquisitions will bring enormous pressure to the staff, leading to a serious of consequences that the staff is very concerned about the changes in his career, job reporting relationships, job differences, and workplace, adapting to the new organizational culture, human resource standards and other issues. Experts called the series of emotional reactions that staff experienced in mergers and acquisitions "Merger mood syndrome". M\&A emotional psychological syndrome reveals a series of changes experienced by employees that are from the denial, fear beginning to final acceptance, the whole process of concern. According to reports, in the process of merger and acquisitions, many former employees of the IBM PC acquisition were very surprised and panic. They even do not want to deal with this reality which is the acquisition of the initial emotional reaction syndrome.

In mergers and acquisitions, layoffs are inevitable. Research shows that during 3000 mergers in 1985, hundreds of thousands of workers lost their jobs or were forced to retire early. In Europe, only in the 1990s, mergers and acquisitions caused 130,000 jobs disappeared in the financial industry. Downsizing not only had a huge impact on layoffs, resulting in a temporary interruption of his career, but also had a very prejudicial influence on the remaining staff. They will thus produce frustration and a sense of loss, as well as distrust of management and uncertainty about their future. This will cause frustration, disappointment and dissatisfaction in survivors. They will not stop discussing their feelings, whether there will be further layoffs, as well as prevent themselves from being laid off while actively looking for energetic job opportunities outside the company, wasting valuable time.

Research is shown that both the communal cultural differences and cultural management failed merger would result in significant adverse effects on the final result of the acquisition. Talk about the problems of corporate mergers and acquisitions without cultural differences tend to gradually fail. Failure of cultural integration is part of the main reasons for mergers and acquisitions. Investors have a tendency to hold a negative attitude for obvious cultural differences of both acquisitions. After the merger, both employee groups will think their culture is greater than the other, and want the company culture combined with their imaginative culture more, therefore cultural change is one of the most difficult changes for people to accept.

After the Lenovo acquisition of IBM's PC business, communication was soon carried out, including IBM employees' visit to the Lenovo Research Institute, plants, processes, etc. And it exchanges of both sides of channels. These pragmatic moves are in favor of the integration of personnel, but only these were not enough. More sophisticated communication strategies should be strengthened to achieve resonance between senior managers and staff as soon as possible. Regularly publish a variety of information to all personnel associated with mergers and acquisitions, such as cultural integration, organization and personnel, discipline and operational norms, performance and progress, etc. Ensure that everyone has the right to know, promoting relief of employee stress, and winning their understanding, trust and support. A special agency should be established to communicate and answer questions to ease employees' worry. Management should also strengthen communication to understand the mentality of employees and dispose psychological and alert staff pessimism effectively. When workers understand the latest development of the acquisition and identify their position in the modern enterprise, the risk of M\&A failure can be minimized. Through communication with workers, management can reduce the resistance of the reform of mergers and acquisitions, and promote the smooth merger integration work.

Human resource policies should be timely informed to workers after the merger and layoff decisions should make as quickly as possible. Although it is painful for those employees who will be laid off, but after all, they know the company's decision earlier, which can help arrange their personal future earlier. In the meantime, for those employees who remain, they can quickly understand their role in the new company, responsibilities, and their concerns about the outlook for the future and anxiety can be timely eliminated, reassuring the public and relieve their worry about their work. 


\section{Summary}

Through this research on human resource matching problem and solving methods of the Lenovo acquisition of IBM PC business, we can see a lot of companies will face matching problems of the human resources in the post-merger, and solving these problems is key to developing smoothly and healthily after M\&A. The psychological and emotional appease to improve work and emotional stability of employees after the merger is a priority to solve the matching problem for the company's human resources department. Only by solving the psychological problems of employees to retain key personnel can we ensure the smooth progress of the company after the merger and achievement of the purpose of the acquisition.

\section{Acknowledgements}

This work was financially supported by the Natural Science Foundation of Shandong Province (ZR2012FM013).

\section{References}

[1] Collins, C. J., \& Smith, K. G. Knowledge exchange and combination: The role of human resource practices in the performance of high-technology firms. Academy of Management Journal, 49, (2006), p. 544-560.

[2] Cheng, D. J., \& Zhao, S. M. HPWS and firm performance: Impacts of Human capital uniqueness and environment dynamics. Management World, 3, (2006), p. 55-64 (In Chinese).

[3] Chen, X., \& Chen, C. On the intricacies of the Chinese guanxi: A process model of guanxi development. Aisa Pacific Journal of Management, 21, (2004), p. 305-324.

[4] Becker, B. E., \& Huselid, M. A. Strategic human resources management: Where do we go from here? Journal of Management, 32, (2006), p. 898-925.

[5] Combs, J., Liu, Y., Hall, A., \& Ketchen, D. How much do high performance work practices matter? A meta-analysis of their effects on organizational performance. Personnel Psychology, 59, (2006), p. 501-528.

[6] Becker, B. E., Huselid, M. A., \& Beatty, R. W. The differentiated workforce: Transforming talent into strategic impact. Boston: Harvard Business School Press. Review, 2(2), (2009), p. 183-203.

[7] Colbert, B. A. The complex resource-based view: Implications for theory and practice in strategic human resource management. Academy of Management Review, 29, (2004), p. 341-358.

[8] Batt, R. Managing customer services: Human resource practices, quit rates, and sales growth. Academy of Management Journal, 45, (2002), p.587-597.

[9] Datta, D. K., Guthrie, J. P., \& Wright, P. M. Human resource management and labor productivity: Does industry matter? Academy of Management Journal, 48, (2005), p. 135-145.

[10] Akhtar, S., Ding, D. Z., \& Ge, G. L. Strategic HRM practices and their impact on company performance in Chinese enterprises. Human Resource Management, 47(1), (2008), p. 15-32.

[11] Gibson, C. B., Benson, G. S., Porath, C. L., \& Lawler, E. E. What results when firms implement practices: The differential relationship between specific practices, firm financial performance, customer service, and quality. Journal of Applied Psychology, 92, (2007), p. 1467-1480.

[12] Banister, J. Manufacturing earnings and compensation in China. Journal of China Labor Economics, 3(2), (2006), p. 39-66. 